of the decreased response of LH and FSH to LHRH in a child of this age. The two sisters reported by Miyai et al. (1971) were said at the age of 12 and 14 years respectively to have early breast development and detectable urinary $\mathrm{LH}$ and FSH. Our patient seems similar to Case 23 of Chaussain et al. (1974) who had TSH deficiency with a normal response to TRH but no significant rise of $\mathrm{LH}$ and FSH with LHRH.

That this sort of case and other cases of congenital secondary hypothyroidism may be missed, is an objection to the use of TSH rather than T4 as the primary test in screening for neonatal hypothyroidism. However, although this patient has a history of hypothyroidism dating back to neonatal life or at least to early infancy, the hypothyroidism was of mild degree with no deficit in intelligence.

We thank Dr Valerie Marrian for referring this case to the endocrine clinic in Dundee, Miss Margaret
Browning and Dr Elizabeth Hunter for endocrine assays, and Dr Constance Forsyth for advice.

\section{References}

Boehm, T. M., Dimond, R. C., and Wartofsky, L. (1976). Isolated thyrotrophin deficiency with thyrotrophinreleasing-hormone induced TSH secretion and thyroidal release. Journal of Clinical Endocrinology and Metabolism, 43, 1041-1046.

Chaussain, J. L., Garnier, P. C., Binet, E., Vassal, J., Scholler, R., and Job, J. C. (1974). Effect of synthetic luteinizing-hormone-releasing hormone (LH-RH) on the release of gonado-trophins in hypophyso-gonadal disorders of children and adolescents. III. Hypopituitarism. Journal of Clinical Endocrinology and Metabolism, 38, 58-63.

Kaplan, S. A. (1975). Hypopituitarism. In Endocrine and Genetic Diseases of Childhood and Adolescence, second edition, pp. 106-126. Edited by L. I. Gardner. Saunders: Philadelphia.

Miyai, K., Azukizawa, M., and Kumahara, Y. (1971). Familial isolated thyrotrophin deficiency with cretinism. New England Journal of Medicine, 285, 1043-1048.

Correspondence to Dr P. J. Smail, Department of Child Health, Ninewells Hospital and Medical School, Dundee DD1 9SY.

\title{
Ring 20 chromosome in a child with seizures, minor anomalies, and retardation
}

\author{
JANET M. STEWART, NICHOLAS CAVANAGH, AND DAVID T. HUGHES \\ Institute of Child Health, and The Hospital for Sick Children, London
}

SUMmARY A patient is reported with seizures, developmental delay, and minor physical anomalies. Karyotype showed a ring formation of chromosome number 20. Previously reported patients with this chromosomal aberration have typically had seizures and behavioural disorders with considerable variation in the degree of physical abnormality and mental retardation. A correct diagnosis in such a case is important for accurate genetic counselling.

Many new chromosomal syndromes have been reported since the introduction of banding. Most of these are associated with dysmorphic features, multiple anomalies, and mental retardation. A ring formation of chromosome 20 , on the other hand, has been reported in patients with negligible physical anomalies, severe seizures, and variable retardation (Table). We report an additional case to emphasise that seizures with slight dysmorphism may be a manifestation of a chromosomal abnormality.

\section{Case report}

Case 1 was the product of an uncomplicated, term pregnancy and weighed $2800 \mathrm{~g}$ at birth. He was a slow feeder initially. He smiled at 7 weeks, sat unsupported at 10 months, crawled at 14 months, and pulled to stand at 20 months. He had no speech at 25 months. At 12 months he was noted to have episodes lasting 30 minutes in which his head turned to the left and his eyes were glazed. By 14 months he was having spells lasting 20 seconds with mouthing movements and twitching of the right arm and leg, followed by excitement. These occurred up to 5 times daily and continued when he was placed on phenobarbitone.

His mother was 36 and his father 39 at the time of his birth. His mother had a nodular goitre. She had had one miscarriage before the patient's birth and has had one subsequently. She has a brother with a cleft lip and palate and an uncle with well-controlled epilepsy. There was no consanguinity.

When examined at 16 months, his weight was at the 10th centile, height at the 25 th, and head circumference between the 10th and 25 th $(46.5 \mathrm{~cm})$ (Fig. 1). Although his face was not strikingly unusual, he did not resemble either parent. He had a sloping forehead, synophrys, long eye lashes, and no epicanthic folds. The nose was small and flattened and he had a long philtrum. The palate was 


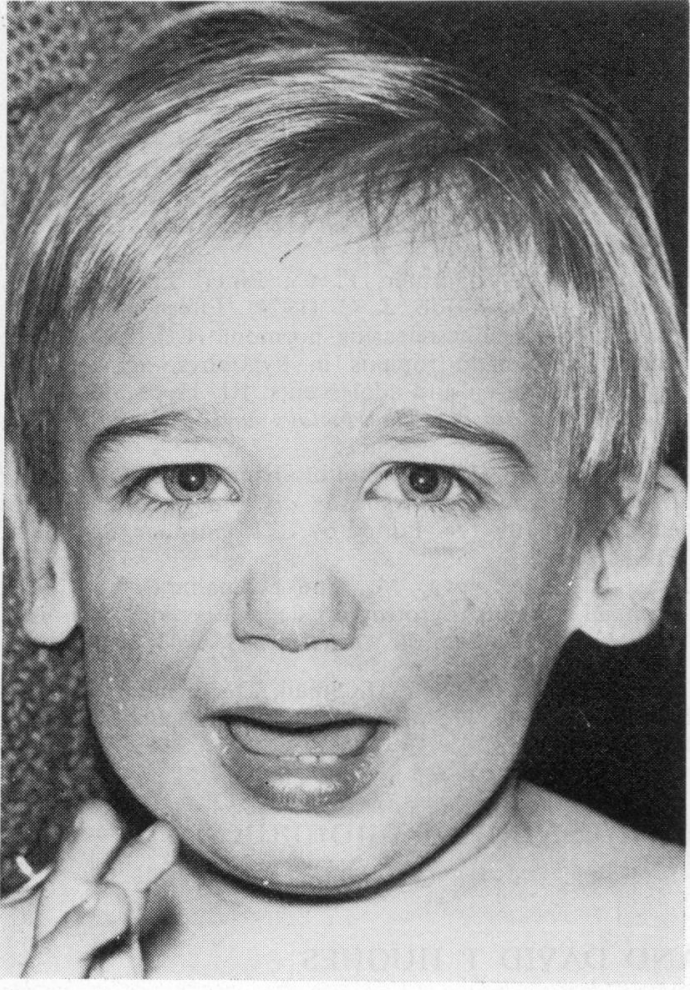

(a)

moderately high arched and there was micrognathia. The ears were posteriorly rotated and prominent with a poorly developed antihelix. Both testes were descended and he had a glandular hypospadias. He had scattered eczematous patches. There was a groove between the first and second toes, but palmar creases and dermatoglyphics were otherwise unremarkable. Neurological examination was normal except for mild hypotonia.

Routine blood studies including amino-acids, immunoglobulins, and a congenital infection screen were normal. Other normal studies were CAT, electroretinogram, and skull films. An electroencephalogram showed occasional paroxysmal features without clear lateralisation. On the Griffiths's developmental chart he functioned at the 12-month level. A G-banded karyotype showed 3 normal cells and 21 cells with a ring 20 chromosome $(46, X Y / 46$, XY20r Fig. 2). Both parents had normal karyotypes. At the parents' request fibroblast cultures were not done.

\section{Discussion}

A ring chromosome is formed by the partial deletion of both the long and short arms with rehealing

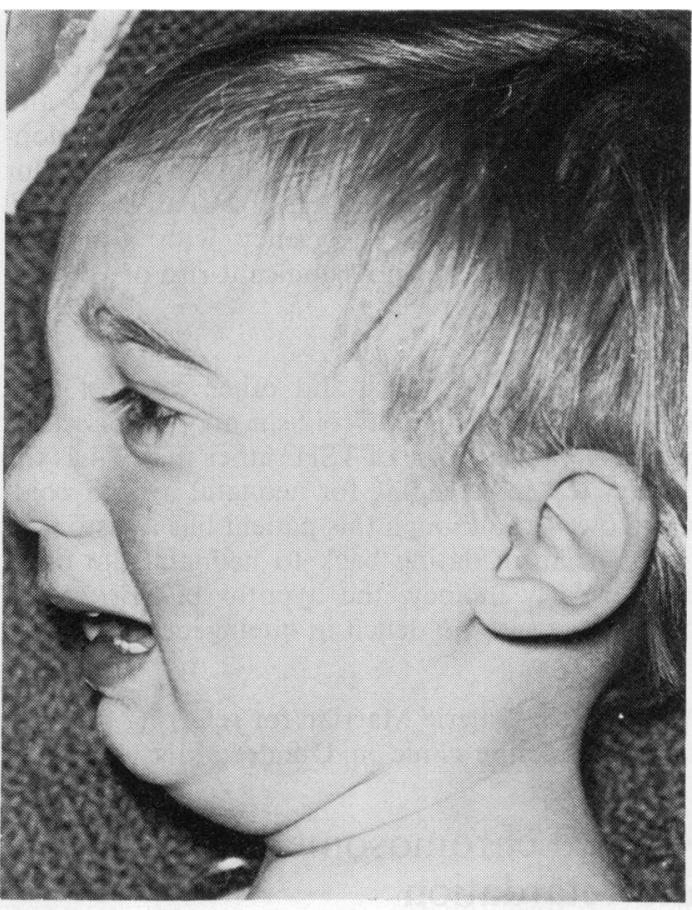

(b)

Fig. 1 Facial appearance of patient, (a) full face and (b) profile.

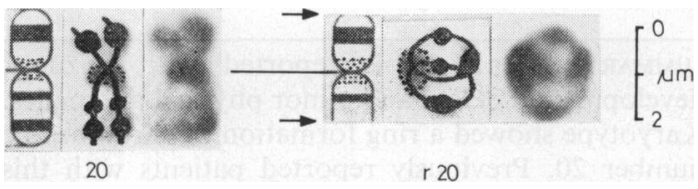

Fig. 2 Giemsa-banded chromosomes showing, from left to right, drawing and photomicrograph of the normal and the ring chromosome no. 20 (International Standard Diagram).

in a ring formation. This is an unusual abnormality and often unstable.

Previous cases. Four other patients with a ring 20 chromosome have been reported (Table). Atkins et al. (1972) described a 7-year-old boy (Case 2) with the ring present in most of the cells. Behaviour problems began at one year and grand mal seizures at $6 \frac{1}{2}$. His physical examination was said to be normal and IQ was estimated at 50. Faed et al. (1972) reported an 11-year-old boy (Case 3) with a ring 20 in $60 \%$ of his cells. He too was said to be of normal appearance except for bilateral epicanthi and unusual dermatoglyphics. Temporal lobe seizures started at age 4 . They were poorly controlled and associated with behavioural deterioration. His IQ 
Table Patients with a ring 20 chromosome

\begin{tabular}{|c|c|c|c|c|c|c|c|c|c|}
\hline Case & Report & Date & $\begin{array}{l}\text { Age } \\
\text { (years) }\end{array}$ & $\begin{array}{l}\text { Mental } \\
\text { retardation }\end{array}$ & Seizures & $\begin{array}{l}\text { Behaviour } \\
\text { disorder }\end{array}$ & $\begin{array}{l}\text { Dysmorphic } \\
\text { features }\end{array}$ & Karyotype & $\begin{array}{l}\% \text { of cells } \\
\text { with ring } 20\end{array}$ \\
\hline 1 & Present case & 1979 & 2 & + & + & - & \pm & $46, X Y 20 r / 46, X Y$ & 88 \\
\hline 2 & Atkins et al. & 1972 & $\overline{7}$ & $+(50)$ & + & + & 二 & $46, X Y 20 r / 45, X Y-20 r$ & 94 \\
\hline 3 & Faed et al. & 1972 & 11 & $\pm(80)$ & + & + & $\pm^{*}$ & $\begin{array}{l}46, X Y 20 r / 46, X Y \\
\text { (3/10 fibroblasts) }\end{array}$ & 60 \\
\hline 4 & Uchida and Lin & 1972 & 23 & $+\dagger$ & + & + & - & $46, \mathrm{XX} 20 \mathrm{r} / 46, \mathrm{XX}$ & 22 \\
\hline 5 & Jacobs et al. & 1978 & 27 & $+(18)$ & + & $?$ & - & $46, X Y 20 r$ & 100 \\
\hline 6 & de Grouchy et al. & 1972 & $6 / 12$ & + & + & - & + & $46, X Y$ Fr & 100 \\
\hline
\end{tabular}

* Epicanthic folds only, tnormal development until grade 6.

was 80. A 23-year-old woman (Case 4) was reported by Uchida and Lin (1972) with a ring 20 in $22 \%$ of her lymphocytes, the remaining cells being normal. She was said to have developed normally as a child although she was a 'crib rocker', a head banger, and had nightmares. 'Petit mal' began at age 10 years and grand mal seizures at age 12 . Her developmental progress ceased at grade 6 (about 12 years). Her behaviour was erratic, impulsive, and juvenile. She had hyperreflexia and was clumsy in performing finer movements; no dysmorphic features were described. Her IQ was 62. Case 5 was found by Jacobs et al. (1978) when screening patients in an institution for the retarded. He had a ring 20 chromosome in all cells counted. He was said to have been normal until 18 months when he had a fall with seizure and fever $\left(41 \cdot 1^{\circ} \mathrm{C}\right)$. At age 27 years, he was profoundly retarded, had mild microcephaly, small testes, kyphoscoliosis, and flexion contractures, but as in the other cases, no dysmorphic features were described.

These patients have several features in common: all had seizures and 3 had behavioural abnormalities of various types (aggressive, immature, impulsive). Intelligence quotients varied from 18 (Case 5) to 80 (Case 3). Our patient also has seizures, developmental retardation, and only minor physical abnormalities. None with a confirmed ring 20 was dysmorphic. However, an infant (Case 6) reported by de Grouchy et al. (1972) had a ring formation of an unspecified $F$ chromosome. This child had a dysmorphic face, severely retarded development, and seizures beginning at 3 months. He died at 7 months of age.

When a child presents with seizures, behaviour disturbance, developmental delay, and either no physical anomalies or minor ones, a karyotype may not be requested. Indeed these are common problems and are only rarely associated with a chromosomal abnormality, yet it is important to know when one does exist. The parents of such a child should receive genetic counselling and the recurrence risk will vary with the cause of the problem. The presence of a chromosomal abnormality in the child and normal karyotypes in both parents implies a low recurrence risk with the option of prenatal diagnosis.
Mental retardation is variable in this and other chromosomal abnormalities and some of these individuals may reproduce. The recurrence risk in their children is then increased (even when the patient is a mosaic) and amniocentesis is clearly indicated.

The possibility of the chromosomal aberration being secondary to anticonvulsants was raised by Atkins. All the reported patients had seizures and were probably on medication. Acquired deletions of chromosome 20 have been described in various haematological disorders, such as polycythaemia vera (Millard et al., 1968) and acute leukaemia (Kiossoglou et al., 1965). The presence of the abnormality in 3 of 10 fibroblasts examined in Case 3 (Table), its restriction to chromosome 20 , and the variety of drugs used make this explanation unlikely.

We thank Dr Edward Brett for allowing us to report his patient and for the many helpful suggestions made by him and by Professor Cedric Carter. We also thank Miss Doreen Farrington and Miss Janette Rae for their help in the cytogenetic laboratory.

\section{References}

Atkins, L., Miller, W. L., and Salam, M. (1972). A ring-20 chromosome. Journal of Medical Genetics, 9, 377-380.

de Grouchy, J., Plachot, M., Sebaoun, M., and Bouchard, R. (1972). Chromosome F en anneau (46, XY Fr), chez un garçon multimalformé. Annales de génétique, 15, 121-126.

Faed, M., Morton, H. G., and Robertson, J. (1972). Ring F chromosome mosaicism $(46, \mathrm{XY}, 20 \mathrm{r} / 46, \mathrm{XY})$ in an epileptic child without apparent haematological disease. Journal of Medical Genetics, 9, 470-473.

Jacobs, P. A., Matsuura, J. S., Mayer, M, and Newlands, I. M. (1978). A cytogenetic survey of an institution for the mentally retarded. I. Chromosome abnormalities. Clinical Genetics, 13, 37-60.

Kiossoglou, K. A., Mitus, M. J,, and Dameshek, W. (1965). Chromosomal aberrations in acute leukemia. Blood, 26, 610-641.

Millard, R. E., Lawler, S. D., Kay, H. E. M., and Cameron, C. B. (1968). Further observations on patients with a chromosomal abnormality associated with polycythaemia vera. British Journal of Haematology, 14, 363-374.

Uchida, I. A., and Lin, C. C. (1972). Ring formation of chromosomes Nos. 19 and 20. Cytogenetics, 11, 208-215.

Correspondence to Dr N. Cavanagh, Department of Neurology, The Hospital for Sick Children, Great Ormond Street, London WC1N 3JH. 